\title{
Leila Leite Hernandez, Filhos da terra do Sol - a formação do estado-nação em Cabo Verde, São Paulo, Selo Negro, 2002, 217 p., ISBN : 858747819-2.
}

Este livro compreende um período histórico que vai das origens do povoamento das Ilhas de Cabo Verde no século XV à transição democrática nos inícios dos anos noventa do século xx. Ele aborda os temas mais diversos desde a sociedade esclavagista e o tráfico negreiro, à propriedade da terra, às revoltas, a colonização, as classes sociais, a estrutura política-administrativa, o nacionalismo, o pan-africanismo, a luta armada, a relação entre a vanguarda e as massas, a independência, as dissenções, os principais desafios actuais. Relacionadas com esses temas analisa várias questões como o "carácter específico da colonização portuguesa », o papel de Cabo Verde «no sistema atlântico da política ultramarina portuguesa », " as características responsáveis pela constituição da sociedade caboverdeana », as condições históricas por meio das quais se formou o processo de contestação do colonialismo e a emergência do novo movimento emancipatório. A abordagem da L. L. Hernandez para compreender um tão vasto período histórico e um tão variado número de temas e questões consiste na «reconstrução histórica » que procura recuperar, segundo a autora, «o processo histórico de constituição e desenvolvimento da sociedade caboverdeana de acordo com os seus principais actores, os caboverdeanos ». Dada a amplitude do trabalho a autora chama-nos a atenção pela «tensão contínua entre os temas » e um certa «falta de simetria ». È precisamente esta tensão e as assimetrias que nos levam a seleccionar apenas alguns dos grandes temas, a saber as raízes, o pan-africanismo, a emancipação nacional.

A tese avançada pela autora segundo a qual «o processo de formação da consciência nacional marcando o momento pelo qual no contraste com a cultura ocidental afirma-se uma cultura, um povo, que não existe como nação, mas certamente existe como entidade cultural » não parece ser demonstrada ao longo do trabalho ; pelo contrário, há mesmo afirmações que a contrariam plenamente. Cito como exemplo a referência feita pela autora ao papel da diáspora como factor de criação de uma «comunidade imaginada » que é, na citação de Benedict Anderson, « imaginada porque nem mesmo os membros das menores nações jamais conhecerão a maioria de seus compatriotas, nem os encontrarão, nem sequer ouvirão falar deles, embora na mente de cada um esteja viva a imagem da sua comunhão »(p. 126). Essa relação leva a autora a afirmar que paradoxalmente, « a emigração está relacionada, directamente, com o processo pelo qual se forma a consciência nacional ». Se levarmos em conta que a emigração sucedeu quase imediatamente o fim da tráfego negreiro no século XIX devemos concluir que essa consciência ou pelo menos as suas palpitações já se registavam nessa época. Uma outra fonte dessa consciência nacional advém das revoltas dos escravos e dos rendeiros cujo valor e importância foram subestimados pela autora. Os trabalhos recentes do historiador A. Correia e Silva sobre um movimento com características dos quilombos na localidade de Julanque, que infelizmente são posteriores ao trabalho da autora, teriam podido ajudar à uma melhor compreensão.

A autora mostra que as raízes da sociedade caboverdeana são rizomas que se espalham em diversas direcções. A reconstrução histórica feita do período esclavagista mostra Cabo Verde como um centro estratégico do comércio triangular onde as mercadorias vindas da Europa seriam trocadas por escravos transportados 
para a América, em particular para o Brasil, onde produziam os produtos tropicais, café, tabaco, açúcar, algodão e cacau que seriam vendidos na Europa a troco de dinheiro. Os investimentos dos negreiros para estas operações eram muito exigentes e levavam três a quatro anos para a sua rentabilização. Estes investimentos eram avultados mas os rendimentos resultantes dessas operações eram enormes. Cabo Verde era neste circuito um ponto de maior segurança em relação às feitorias implantadas no continente africano, quer para o abastecimento dos navios quer para a produção de algumas mercadorias que podiam também entrar no tráfico como a aguardente, a urzela, o indigo, os panos e as vacas. Algumas dessas mercadorias produzidas localmente deram alguma autonomia aos «moradores » que em alguns momentos eram concorrentes dos «reinóis ». A produção dessas últimas mercadorias necessitava também de mão-de-obra escrava que devia por conseguinte ficar nas ilhas. Acabou por se constituir um duplo sistema, um conduzido por negreiros «reinóis» que utilizavam as ilhas como um ponto de apoio à circulação geral dos escravos e outro por «moradores », proprietários de terra e negreiros, que pretendiam rentabilizar a mão-de-obra escrava in loco. As referências feitas pela autora às proibições decretadas pelos reis resultaram exactamente dessas contradições entre interesses divergentes. A análise do «Tratado Breve dos Rios da Guiné do Cabo Verde » (1594), de André Álvares d'Almada, infelizmente pouco explorado pela autora, permitiria aprofundar melhor essas contradições. O dispositivo ${ }^{1}$ de Álvares d'Almada consiste na organização do Império pela criação de um novo pólo descentrado, uma espécie de delegação da « dominação », que passaria pela subalternização do Brasil (estamos a pouco mais de cinquenta anos da «descoberta » do Brasil), a construção de um pólo de reabastecimento do comércio com a Índia e a utilização da força de trabalho dos escravos em África e não fora dela, a sua ocupação pelos « moradores » de S. Tiago (Cabo Verde) e a «assimilação » dos reis africanos através da cristianização.

O sistema negreiro levou à criação na Ribeira Grande de um empreendimento de «ladinização » ou seja de atribuição de alma aos escravos negros através do baptismo e dos ensinamentos de rudimentos de latim e da catequese. Esses escravos tinham um destino diferente dos demais, os escravos «boçais », na medida em que eram maioritariamente empregues no Brasil como escravos domésticos e não nas plantações. Esta enorme tarefa ultrapassava a capacidade do clero « reinol» e levou à formação de um clero autóctone que em 1652 pôde impressionar o Padre António Vieira, na sua passagem a caminho do Brasil, onde encontrou «padres negros como azeviche » que por serem tão sapientes e conhecedores do latim podiam suscitar inveja dos padres do reino. Começava deste modo a classe de letrados que iria mais tarde, com a introdução da Imprensa Nacional, em 1842, produzir uma literatura virada para as questões nacionais, o que se designa por nativismo. A autora podia ter visto essa relação e poderia deste modo situar melhor as origens da intelectualidade que ela trata com muita pertinência e rigor.

Ao abordar o pan-africanismo a autora realça a sua afinidade com o conceito de raça tal como foi elaborado pelo pensamento ocidental no século XIX. Se os ideais biológicos e éticos da Europa e dos EUA do século XIX inspiraram a

${ }^{1} \mathrm{O}$ dispositivo é aqui tomado no sentido de M. Foucault ou seja como «estratégias de relações de força, apoiando, e apoiadas por, tipos de conhecimento », in Power/Knowledge, Brighton, Harvester Press, 1980, p. 196. 
construção pan-africanista do século XX, o contexto específico da dominação dos afro-descendentes nos Estados Unidos foi o quadro social a partir do qual os intelectuais afro-americanos, em particular Du Bois e Crummell, elaboraram as principais concepções. Apesar da tentativa de uma concepção sócio-histórica de raça que se encontra em Du Bois, este autor acaba por recair na ideia biológica do «sangue comum » e no sentimento de raça como família tal como se encontra em Crummell. O pan-africanismo ao recriar uma identidade africana baseada nas tradições leva a uma minimização da diversidade cultural e identitária dos africanos. Essa uniformização pode ter tido algum impacto na adesão relativa dos ideais pan-africanos na intelectualidade cabo-verdeana. Essa especificidade, apresentada muitas vezes como um fenómeno da mestiçagem, analisada em completo desfasamento com a estrutura sociológica, como se os mestiços fossem uma camada social, deve-se sobretudo à história do colonialismo em Cabo Verde e São Tomé e Príncipe, podendo ser considerada como anterior à dos outros povos continentais, para quem a colonização propriamente dita só pode realmente ser assim classificada a partir do século XIX.

A história do movimento de emancipação acabou por ser pouco crítica da história oficial e podia ter aprofundado melhor alguns aspectos que deixa apenas entreabertos, nomeadamente as contradições e cisões no seu seio. A primeira diz respeito às tensões entre os caboverdeanos e os guineenses no seio do PAIGG que se agravaram com a política de «Guiné Melhor» levada a cabo pelo governador Spínola que visava separar a direcção do movimento nacionalista das bases que o suportavam. O governador colonial, seguindo as lições da guerra de Vietnam, procurou transformar a guerra nacional em guerra civil. A criação dos Comandos Africanos, a organização dos Congressos do Povo e a organização de manifestações de rua em Bissau contra a presença dos caboverdeanos na Guiné faziam parte dessa estratégia. Esta teve consequências fortes no interior do PAIGG e exacerbou a distância entre a direcção e a base, que sociologicamente tinham uma composição distinta. A direcção era predominantemente composta por membros saídos das classes urbanas, na sua maioria crioulos, com formação e educação portuguesa, entre os quais se encontrava um bom número de caboverdeanos e luso-guineenses. A base era composta por camponeses oriundos de várias etnias, entre os quais havia um predomínio de camponeses balantas. Apesar da heterogeneidade do movimento nacional, a unidade se fazia em torno dos objectivos da independência dos dois países graças à capacidade de liderança e ao génio de Amílcar Cabral. A estratégia spinolista teve uma forte acção de erosão dessa unidade que se tornava cada vez mais difícil de manter à medida que as exigências da luta prolongada aumentavam e que alguns privilégios, ainda que mínimos, eram acordados à direcção baseada em Conakry. Pode-se certamente afirmar que a morte de Amílcar Cabral resulta dessa erosão. O PAIGG teve ainda recursos para recriar uma unidade que se manteve ainda por alguns anos, o tempo necessário para obter as independências na sequência do 25 de Abril em Portugal e criar as primeiras bases do Estado até 14 de Novembro de $1980^{2}$. A autora podia ter melhor analisado esta crise se ela a tivesse visto como a continuação da crise que tinha

${ }^{2}$ Data do golpe de estado liderado pelo então primeiro-ministro Nino Vieira à frente do «Movimento Reajustador». Paradoxalmente, nessa noite o cinema de Bissau passava o filme Estado de Sítio de Costa-Gavras. 
levado à morte de Amílcar Cabral. O « Movimento Reajustador » relança o nacionalismo guineense e procura unir as diversas facções da sociedade guineense que tinham participado quer na política da Guiné Melhor quer nos movimentos nacionalistas que se tinham oposto ao projecto unitário do PAIGC. Esta unidade faz-se pelo relançamento de uma nova reconstrução identitária, a dos filhos do chão, ou seja de uma autenticidade autóctone dos verdadeiros filhos da Guiné que é necessariamente excludente em relação aos caboverdeanos e seus descendentes, considerados a partir de então como burmedju ${ }^{3}$, passando estes a ocupar postos cada vez mais subalternos na hierarquia do Estado. Este movimento é gerador de novas contradições cuja análise merece a pena ser efectuada a fim de se compreender as crises actuais da Guiné-Bissau.

Finalmente, quando a autora se refere às disputas « acirradas » relacionadas com o grupo de militantes provenientes de Lisboa como sendo «o principal problema do partido desde 1975 até ao expurgo dos elementos mais radicais em 1979 » procura mostrar que esse grupo estava dividido por tendências políticas que coincidiam com origens distintas entre as ilhas do Barlavento e do Sotavento, constatamos na análise simplismo e ingenuidade. Uma leitura mais atenta dos acontecimentos históricos poderia ter feito ver que a partir do 25 de Abril de 1974, a formação do Governo de Transição em Dezembro de 1974, as mobilizações e a recepção do Secretário-Geral do PAIGG em Fevereiro de 1975 pressupunham a existência de um alto grau de organização interna do PAIGG que pouco deve à direcção que se encontrava no exterior. $O$ grupo a que a autora faz referência não se distinguia pelas origens geográficas mas pela sua grande juventude, forte entusiasmo e uma influência das ideias revolucionárias que mobilizavam a juventude de todo o mundo nessa época, em particular as que resultavam da crítica ao socialismo real e ao modelo estalinista de construção do Estado. As divergências surgem de diferenças entre gerações políticas e entre as perspectivas « realistas » e «utópicas » da construção do Estado. As diferenças entre as ilhas acabam por ter significado quando a construção do Estado privilegia o modelo patrimonialista de distribuição dos privilégios no seio do grupo dirigente. Por razões históricas que não cabe aqui analisar, a direcção do PAIGG do « exterior », que assumiu a direcção do Estado, é principalmente originária das ilhas de Barlavento. Este conjunto de circunstâncias desencadeou um movimento identitário santiaguense $^{4}$ que se sentia excluído das esferas do poder. Este foi um dos factores determinantes no apoio dos santiaguenses à organização do principal movimento de oposição, o MpD, cujo núcleo central era o « grupo » dissidente referido anteriormente. Essa adesão e o peso demográfico que representa pesou fortemente para a vitória da oposição nas eleições democráticas de 1990. A estes factores se deve acrescentar a forte influência da Igreja Católica nessa oposição e sobre os santiaguenses.

\section{Outubro de 2007, Raul Mendes Fernandes}

\footnotetext{
${ }^{3}$ Termo para designar mestiços entre brancos e negros que não envolve apenas os caboverdeanos ou os seus descendentes mas os filhos de portugueses, de libaneses e outros grupos de epiderme clara.

${ }^{4}$ Os habitantes da Ilha de Santiago representam uma maioria no conjunto do arquipélago.
} 